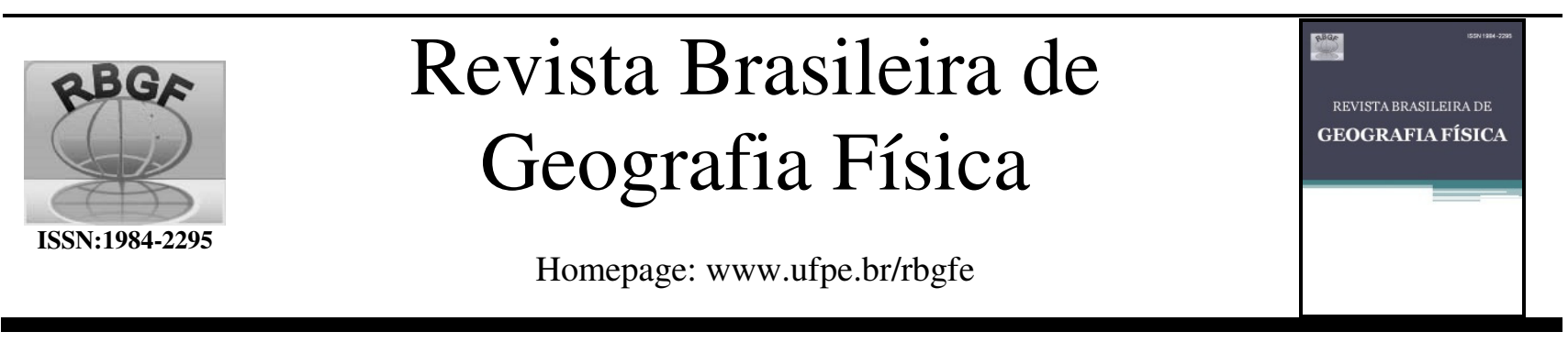

\title{
A Inserção Antrópica no Modelamento da Paisagem Costeira da Zona de Expansão do Município de Aracaju/SE
}

\author{
Luana Santos Oliveira ${ }^{1}$, Ana Cláudia da Silva Andrade ${ }^{2}$
}

${ }^{1}$ Doutoranda em Geografia, Núcleo de Pós-Graduação em Geografia, Universidade Federal de Sergipe. Email: oliveiras.lua @gmail.com; ${ }^{2}$ Prof. do Programa de Pós-Graduação em Análise de Bacias e Geociências, Universidade Federal de Sergipe.

Artigo recebido em 26/06/2014 e aceite em 02/02/2015

\section{R E S U M O}

A paisagem costeira da Zona de Expansão de Aracaju, Sergipe, NE do Brasil, tem apresentado um aumento no nível de ocupação nas últimas décadas, fato que vem provocando mudanças na forma e estrutura da paisagem natural. Destarte, o presente estudo, visa a analisar a evolução da paisagem natural e antrópica da Zona de Expansão de Aracaju no período ente 1965 e 2008. Os procedimentos metodológicos utilizados foram: levantamento bibliográfico, trabalho de campo e mapeamento das unidades de paisagem em diferentes anos (1965, 1971, 1978, 1986, 2003 e 2008). As unidades de paisagem foram individualizadas em: Terraço Marinho, Duna/Interduna, Planície de Maré, Praia/Duna Frontal e Intervenção Antrópica. Os dados obtidos apontam que após a década de 80 ocorreu o aumento de áreas ocupadas e parcialmente ocupadas sobre as unidades de paisagem natural, resultando em um processo de antropogenização da paisagem. A ocupação está disposta na paisagem de forma dispersa, o que lhe confere um padrão reticulado, padrão este que no caso da área estudada conflita com a disposição das unidades naturais. Com base nos resultados obtidos nesta pesquisa, enfatiza-se a importância do planejamento da ocupação sobre as unidades de paisagem natural, a fim de evitar e minimizar futuros problemas urbano-ambientais.

Palavras-chave: unidades de paisagem, antropogenização da paisagem, dinâmica natural.

\section{The Anthropic Insertion in the Landscape Coastal Modeling at Zona de Expansão de Aracaju/SE}

\section{A B S T R A C T}

The coastal landscape of the "Zona de Expansão", located in Aracaju City, State of Sergipe, Brazilan North East, has been increasing its level of human occupying for the last decades. This fact has been improving changes about shape, structure and function of the natural landscape. In due to demonstrate this reality, the present study aims to analyze the natural and anthropogenic landscape of the Zona de Expansão de Aracaju evolution between 1965 and 2008. The methodology devices used in order to reach this goal included literature survey, fieldwork and units landscape mapping through the years 1965, 1971, 1978, 1986, 2003 and 2008. Landscape units found were classified as Marine Terrace, Dune/Interdune, Tidal Plain, Beach/Foredune and Anthropogenic Intervention. The data collected show an increasing of full and partial occupation over the natural landscape after the 1980's which resulted in a process of landscape anthropic insertion. The occupation is spread over the landscape like a reticulated pattern. This aspect conflicts to the natural units layout. Based on the results obtained, this research emphasizes the importance of occupation planning in order to prevent or at least minimize urban-environmental issues or unbalances in the future.

Keywords: landscape units, antropogenic landscape, natural dynamics.

\section{Introdução}

A paisagem apresenta-se como o resultado material da junção entre o meio natural e o meio

* E-mail para correspondência:
paulomegna@ig.com.br (Francisco, P.R.M.). antrópico (Bertrand, 1972; Bolos, 1992; Ingegnoli, 2002; Rodriguez et al., 2004, Tricart, 1976). As transformações da paisagem ocorrem em escalas temporais distintas, cujos agentes modeladores variam de importância a depender da 
escala. As escalas temporais no estudo da paisagem englobam: longo prazo - dinâmica natural, médio prazo - dinâmica natural e antrópica e, curto prazo - dinâmica natural e antrópica (Bólos, 1981; Rodriguez, Silva e Cavalcanti, 2004).

Entende-se que as paisagens naturais são modificadas e transformadas tanto na forma, função e estrutura pelo homem ao longo do tempo (Lang e Blaschke, 2009). Assim, o modelamento da paisagem acontecerá variando conforme o agente que tem ação preponderante (Bertrand, 1972).

Dentro desse contexto, a paisagem costeira constitui uma das paisagens que apresenta maior complexidade diante da relação estabelecida entre os elementos físicos (continente, atmosfera $\mathrm{e}$ oceano) e antrópicos. Dentre os elementos físicos que modelam a paisagem costeira, destaca-se a ação das ondas e das correntes e ventos, que pode resultar na movimentação natural do posicionamento da linha de costa (Stive et al., 2002; Esteves, 2003; Davis e Fitzgerald, 2004). Adicionalmente, enfatiza-se a dinâmica de unidades naturais como as dunas e os manguezais. A atuação dos agentes físicos modifica constantemente a zona costeira, dando-lhe uma dinamicidade própria.

A crescente ocupação da faixa litorânea, junto a uma grande valorização e exploração imobiliária da orla marítima, tem causado um incremento no interesse pelos estudos voltados a zona costeira. A orla costeira é fisicamente modificada em consonância com as diferentes demandas sociais resultando em diferentes formas de uso e ocupação (Terich, 1987). Por essa razão, esta é uma paisagem em constante modificação, onde são impressas, por vezes, relações conflituosas entre o homem e o meio natural.

Dentro desse contexto, destaca-se a Zona de Expansão do munícipio de Aracaju/SE (Figura 1), área de estudo da presente pesquisa, a qual nas últimas décadas vem apresentando uma intensificação no processo de ocupação da sua frente litorânea. A referida área foi delimitada no ano de 1982, cuja denominação referia-se a área em expansão do munícipio, ganhando ênfase no cenário de ocupação de Aracaju.

A Zona de Expansão de Aracaju é caracterizada por apresentar uma paisagem frágil com a presença de praias, terraços marinhos, dunas e manguezais. Desta forma, o aumento no nível de ocupação nas últimas décadas tem provocado grandes mudanças na paisagem natural, somado à ausência de planejamento que tem resultado em problemas para a população da área, a exemplo de alagamentos em períodos chuvosos, degradação de dunas, aterramento de lagoas, processos erosivos na linha de costa, entre outros.

Destarte, a presente pesquisa visou a analisar a paisagem da Zona de Expansão de Aracaju, no período de 1965 a 2008, a partir da integração entre dinâmica antrópica e natural, pautando-se na delimitação e análise das unidades de paisagem nas últimas cinco décadas. $\mathrm{O}$ escopo do estudo evolutivo é entender de que modo a ação antrópica se espacializou ao longo do tempo, e como esta intervenção tem alterada a forma, a função e a dinâmica da paisagem. Os resultados desta pesquisa poderão subsidiar o planejamento urbano e ambiental no que concerne à estruturação da ocupação na área estudada, evitando ou minimizando danos ambientais e prejuízos socioeconômicos.

\section{Material e Métodos}

Os procedimentos metodológicos utilizados na elaboração deste trabalho englobaram quatro etapas: Levantamento Bibliográfico, Delimitação das Unidades de Paisagem, Elaboração de Mapas e, Integração e Interpretação dos Dados.

Foram levantados artigos, dissertações, teses, relatórios, entre outros, sobre o tema da pesquisa ou temas correlatos, assim como sobre a área de estudo. Os dados cartográficos, fotografias aéreas e imagens de satélite foram obtidos junto aos órgãos governamentais. Para a coleta dos dados históricos referentes à área estudada foram feitas pesquisas bibliográficas, assim como, foram realizadas visitas a órgãos municipais e estaduais.

Para realização do mapeamento multitemporal, utilizou-se o programa de geoprocessamento ARC GIS 9.3. Os mapas multitemporais de ocupação e das unidades de paisagem foram confeccionados sobre uma base cartográfica composta por fotografias aéreas de 1965, 1971, 1978, 1986 e 2004, ortofotos de 2004 e 2008 e, imagens de satélite de 2003 e 2008. As fotografias aéreas foram georreferenciadas com auxílio do programa Global Mapper 11, tomando por base as ortofotos de 2004. Foi utilizado o sistema de projeção UTM e o datum SIRGAS Brasil 2000 para o georreferenciamento e confecção dos mapas.

Os mapas multitemporais das unidades de paisagens foram confeccionados com base nos aspectos geológico-geomorfológicos e antrópicos delimitados em imagens aéreas e em campo (Tabela 1).

Utilizou-se a metodologia empregada por Lang e Blaschke (2009), denominada de Medidas da Estrutura da Paisagem ou Quantificação da Paisagem. Esta metodologia consiste na análise dos dados provenientes da quantificação dos 
elementos da paisagem, a fim de mensurar as transformações decorrentes do seu processo evolutivo. A área, em quilômetros quadrados, das unidades de paisagem para cada ano foi calculada no programa de geoprocessamento ARC GIS 9.3.1.

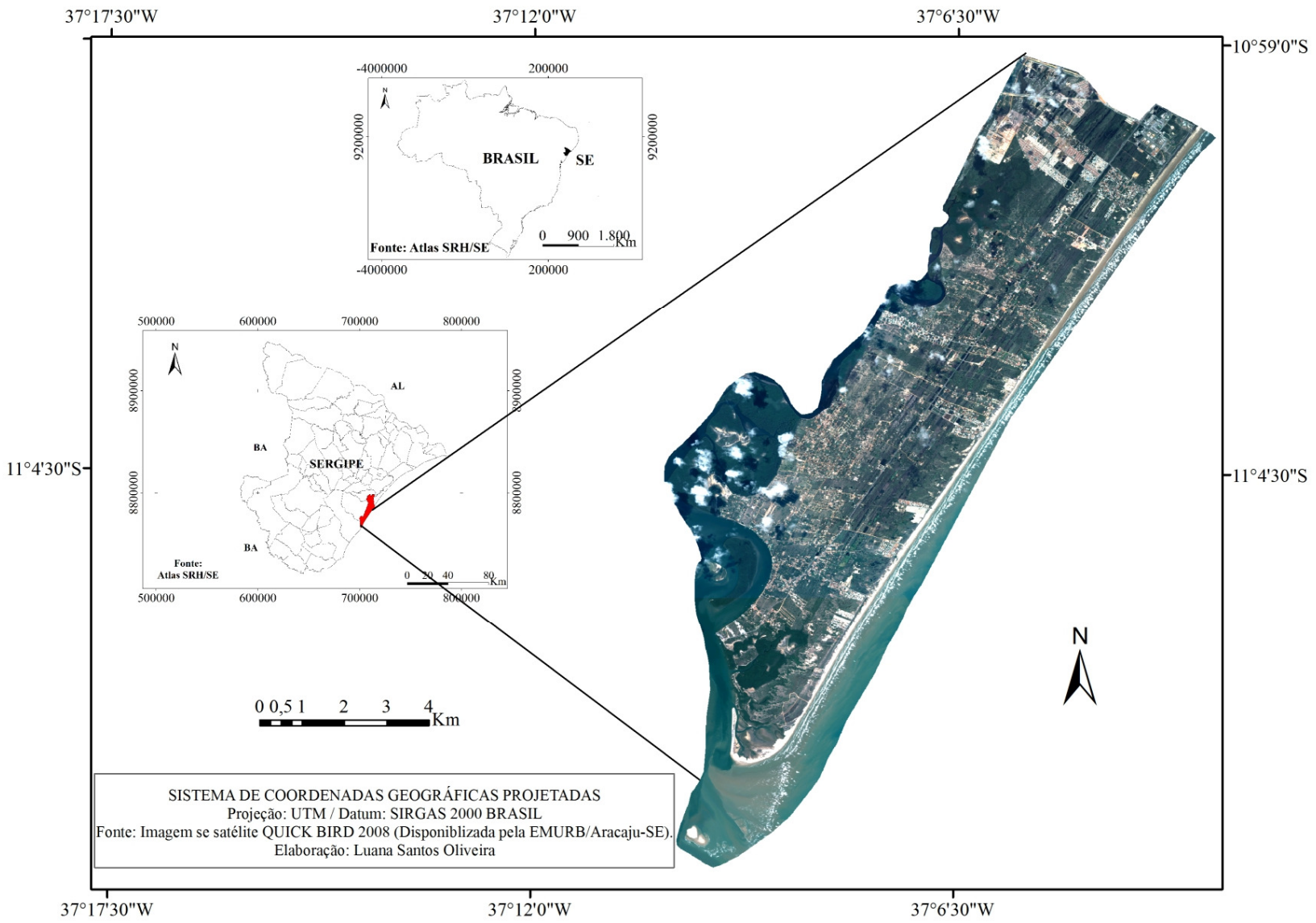

Figura 1. Localização da Área de estudo - Zona de Expansão de Aracaju. Fonte: Imagem de Satélite QuickBird 2008. Organização: Elaboração da autora.

Aplicou-se, ainda, o modelo de ManchaCorredor-Matriz exposto por Lang e Blaschke (2009). Este modelo, utilizado na Ecologia da Paisagem, postula que as áreas naturais podem ser matrizes ou manchas, a depender da sua proporção na paisagem. A matriz constitui mais de $50 \%$ da paisagem, enquanto que a mancha menos de $50 \%$. Já os corredores são considerados como estruturas lineares que servem para a conexão entre os elementos da paisagem. Nesta pesquisa esse modelo foi adaptado, para a análise da antropogeneização da paisagem; as áreas antropizadas podem corresponder às manchas, caso essas compreendam menos que $50 \%$, ou matrizes, caso totalizem mais de $50 \%$ da paisagem. Por outro lado, os corredores correspondem às vias de acesso, que provocam a antropogenização da paisagem.

Os dados levantados nas etapas anteriores foram integrados e interpretados, e, juntamente com o referencial teórico utilizado, permitiu a compreensão da evolução da paisagem costeira da Zona de Expansão de Aracaju/SE a longo, médio e curto prazo.

Tabela 1. Delimitação das Unidades de Paisagem.

\begin{tabular}{ll}
\hline Unidades de Paisagem & Descrição \\
\hline Terraço Marinho & Modelado de acumulação marinha levemente ondulada, caracterizado \\
& pela presença na superfície de cordões litorâneos lineares separados por \\
& terras baixas úmidas. \\
\hline Duna/Interduna & Duna: Modelado de acumulação eólico caracterizado pela morfologia \\
& fortemente ondulada. Interdunas: terras baixas úmidas, situada entre as \\
& dunas, com cordões que registram a movimentação das dunas. Ambas \\
& as áreas (dunas e interdunas) foram atreladas a mesma unidade em \\
& função dos processos que ocorrem nessas. \\
\hline Praia/Duna Frontal & Praia: faixa de areia compreendida entre a linha d'água e a base de \\
\hline
\end{tabular}


escarpas, dunas ou ocupação humana. Duna Frontal: feição de acumulação eólica contígua à praia. O limite entre a Praia e a Duna Frontal nem sempre estava visível nas imagens aéreas, justificando a união das duas feições em uma só unidade.

Planície de Maré Área que bordejam canais de maré e rios, identificada pela presença de sedimentos lamosos recobertos ou não pela vegetação de mangue. A planície de maré é subdividia em: inframaré (porção sub-aquaosa), intermarés (vegetada pelo mangue) e supramaré (área de apicum).

Área de Intervenção Área ocupada: alta densidade de ocupação, identificadas por conjuntos Antrópica habitacionais, casas, condomínios, indústria, bares e restaurantes, que normalmente apresentam formas retangulares;

Áreas parcialmente ocupadas: áreas loteadas cuja ocupação é incipiente, mas que demarcam áreas que provavelmente terão ocupação efetiva. Estas áreas são identificadas a partir do padrão retangular, separado por vias ou não, que diferem das áreas do seu entorno;

- Estradas.

\section{Resultados e Discussão}

Neste estudo considerou-se a paisagem como a união entre Unidade de Paisagem Natural e as Unidades de Intervenção Antrópica, conforme as definições de Bertrand (1972), Bólos (1992) e Rodriguez, Silva e Cavalcante (2004). As Unidades de Paisagem Natural da Zona de Expansão do município de Aracaju compreendem o Terraço Marinho, Duna/Interduna, Praia/Duna Frontal e Planície de Maré. A Unidade de Intervenção Antrópica inclui as Áreas Parcialmente Ocupadas e as Áreas Ocupadas (vide Tabela 1).

As características das Unidades de Paisagem Natural e de Intervenção Antrópica estão descritas a seguir:

O Terraço Marinho equivale ao depósito marinho constituído por sedimentos arenosos e denominado por Bittencourt et al. (1983) de Terraço Marinho do Holoceno. Esta Unidade perfaz grande parte da área de estudo e é caracterizada por apresentar em sua superfície um conjunto de cordões litorâneos (antigas cristas de praia), cuja continuidade é interrompida, em alguns pontos, pelos campos de dunas. A vegetação predominante é a de restinga. Em função da pequena profundidade do lençol freático, algumas áreas no período chuvoso ficam alagadas.

A Duna/Interduna, como a denominação indica, compreende a duna e região entre as dunas. A duna consiste em um depósito arenoso de origem eólica, enquanto a interduna corresponde à área baixa, às vezes ocupada por terras úmidas de água doce. A maior parte das dunas contidas nesta unidade são fixas ou semifixas.

A Praia/Duna Frontal corresponde à faixa de praia associada às feições das dunas frontais, cuja individualização nem sempre foi possível de realizar nas imagens aéreas, sendo por isso agrupadas em uma única unidade.

A Planície de Maré equivale à denominação dos depósitos de mangue aludido por Bittencourt et al. (1983). Esta unidade é caracterizada como a área onde prevalece a ação das marés, identificada pela presença de sedimentos lamosos recobertos ou não pela vegetação de mangue. Os compartimentos da planície de maré incluem a inframaré (sub-aquaosa), intermarés (vegetada pelo mangue) e supramaré (apicum).

As áreas de intervenção antrópica englobam a área ocupada e a área parcialmente ocupada. A Área Ocupada corresponde às áreas de alta densidade de ocupação, identificadas por conjuntos habitacionais, casas, condomínios, indústrias, bares e restaurantes, e que normalmente apresentam formas retangulares. A Área Parcialmente Ocupada corresponde às áreas loteadas cuja ocupação é incipiente, mas que apresentam áreas demarcadas que provavelmente terão ocupação efetiva em futuro próximo. Estas áreas são identificadas a partir do padrão retangular, separado por vias ou não. As vias de acesso, pavimentadas ou não, também fazem parte das Áreas de Intervenção Antrópica.

\section{Evolução das Unidades de Paisagem entre 1965 e 2008}

As Figuras 2 e 3 mostram a espacialização das unidades de paisagem da Zona de Expansão de Aracaju nos anos de 1965, 1971, 1978, 1986, 2003 e 2008. A variação da área (em percentual) das Unidades de Paisagem da Zona de Expansão de Aracaju para os mesmos anos é mostrada no Gráfico 1.

A unidade Terraço Marinho, maior unidade em todos os anos, apresentou um decréscimo da sua área total no decorrer dos anos (1965 e 2008), de cerca de 10,7\% (Gráfico 1). Esta redução foi 
Revista Brasileira de Geografia Física Vol. 08 N. 02 (2015) 391-401

atribuída essencialmente ao aumento da Unidade de Intervenção Antrópica. A ocupação nesta unidade foi marcada pelo aumento de casas, condomínios, estradas e áreas loteadas. Até meados da década de 70 , a ocupação era quase
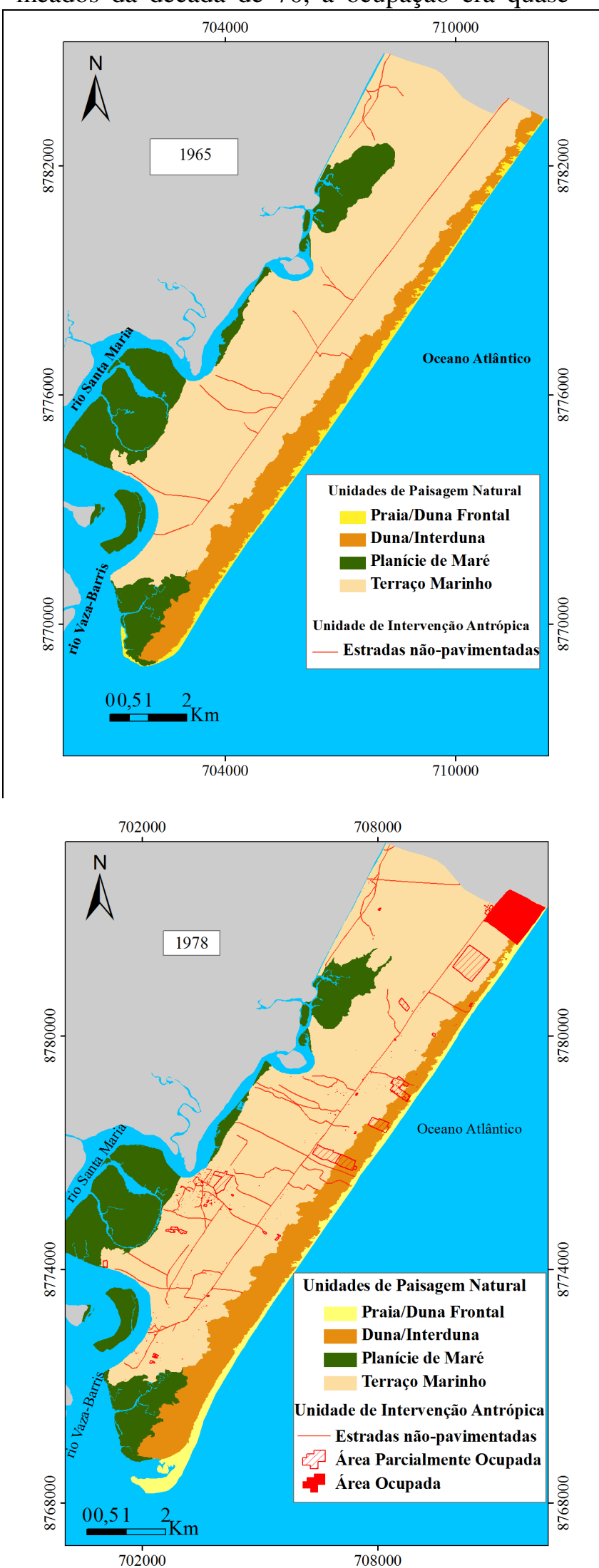

inexistente. Após esta década houve a intensificação da dinâmica antrópica que modificou a estrutura e a forma desta unidade.
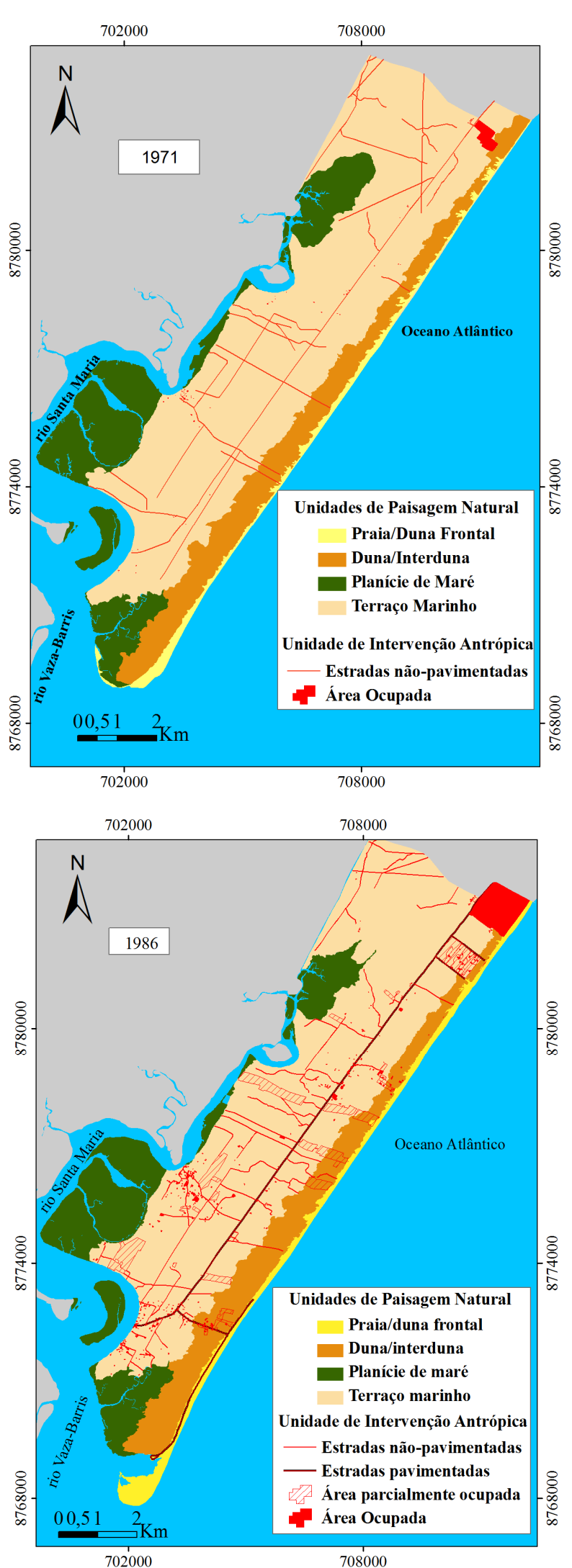

Figura 2. Unidades de paisagem da Zona de Expansão de Aracaju em 1965, 1971, 1978 e 1986. Fonte: Fotografias aéreas de 1965, 1971, 1978 e 1986. Organização: Elaboração da Autora. 
Revista Brasileira de Geografia Física Vol. 08 N. 02 (2015) 391-401

A unidade Duna/Interduna apresentou um decréscimo de 5,1\% em sua área total entre 1965 e 2008 (Gráfico 1). Os maiores decréscimos na área desta unidade ocorreram a partir de 1978, em função do aumento da Unidade de Intervenção

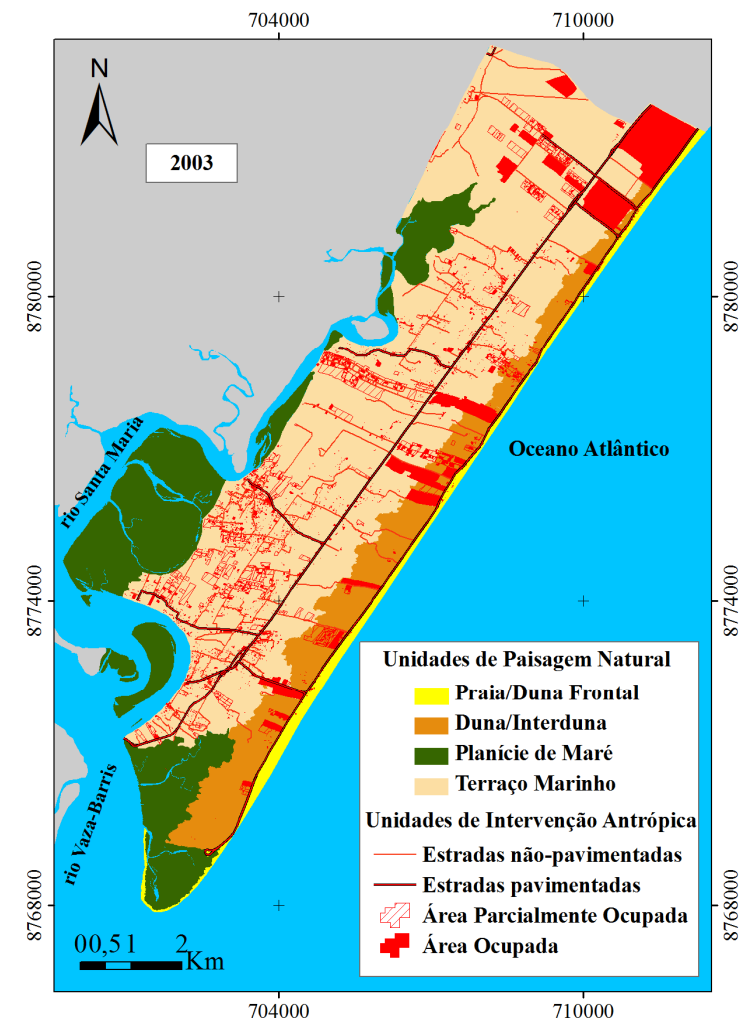

Antrópica. A alteração da área desta unidade ocorre em parte em função da dinâmica dos agentes naturais, a exemplo de eventos sedimentação e erosão.

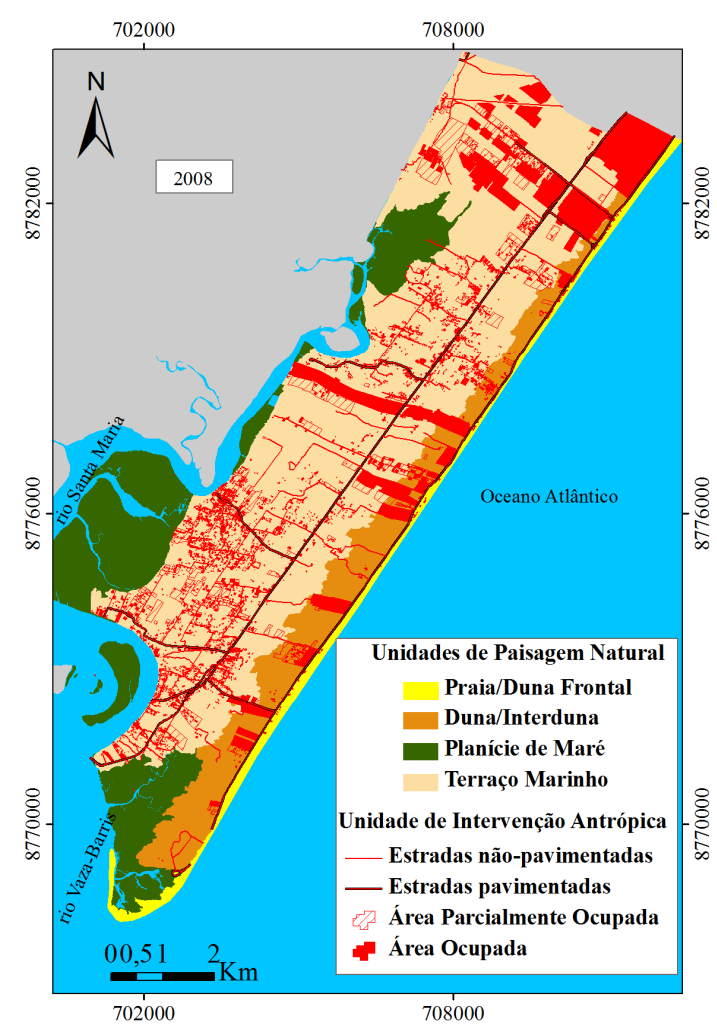

Figura 3. Unidades de paisagem da Zona de Expansão de Aracaju em 2003 e 2008. Fonte: Imagens de Satélite QuickBird 2003 e 2008. Organização: Elaboração da Autora.

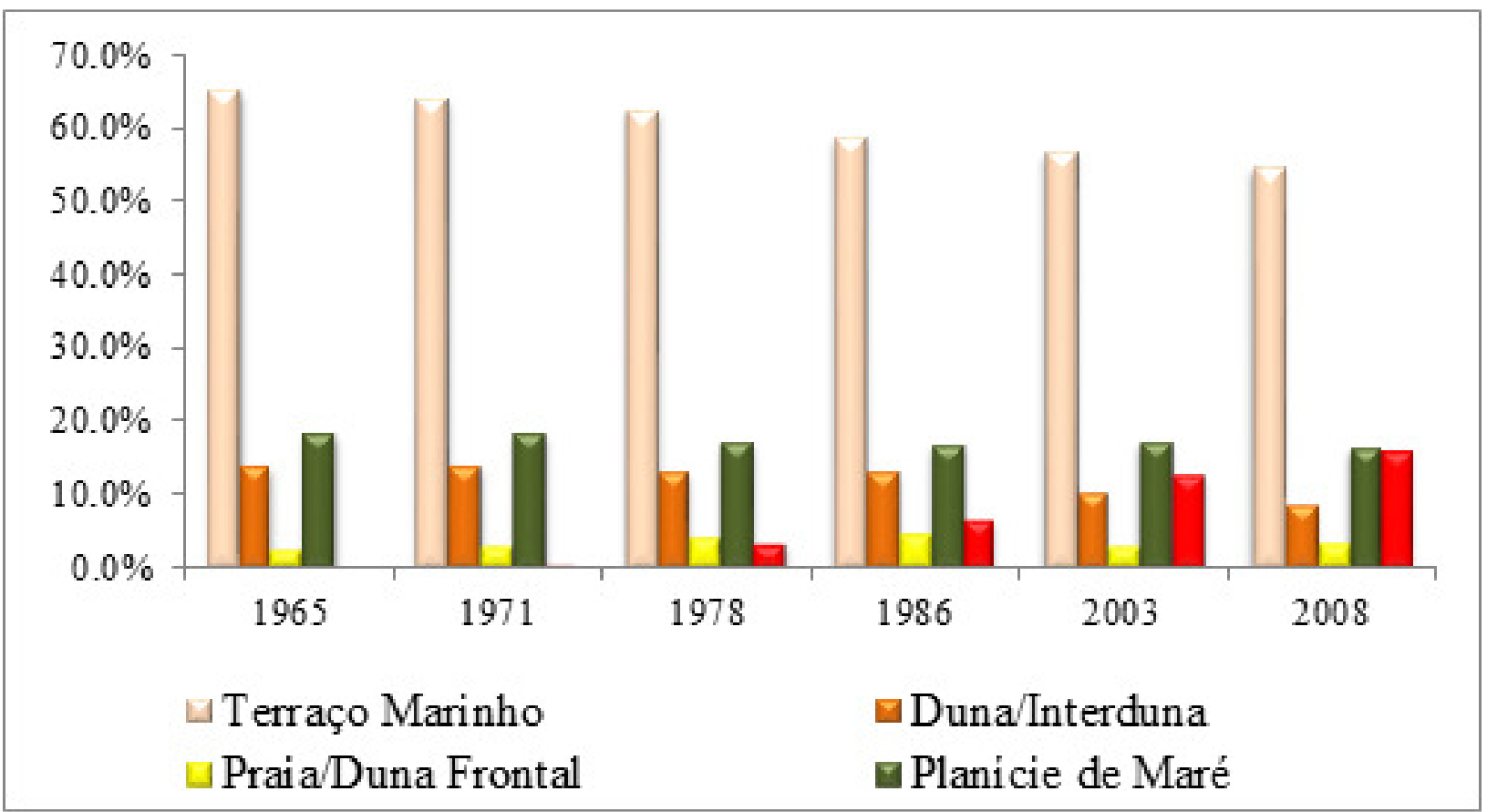

Gráfico 1. Variação da área (em percentual) das Unidades de Paisagem da Zona de Expansão de Aracaju em 1965, 1971, 1978, 1986, 2003 e 2008. Organização: Elaboração da autora. 
A unidade Praia/Duna Frontal obteve baixo valor percentual de alteração em sua área no período analisado. Nesta unidade, a dinâmica natural foi preponderante entre os anos de $1965 \mathrm{e}$ 1986, no qual houve aumento da área de 2,2\%, decorrente do processo de acresção sedimentar ocorrido nas adjacências da desembocadura do rio Vaza-Barris (Figura 4ab).

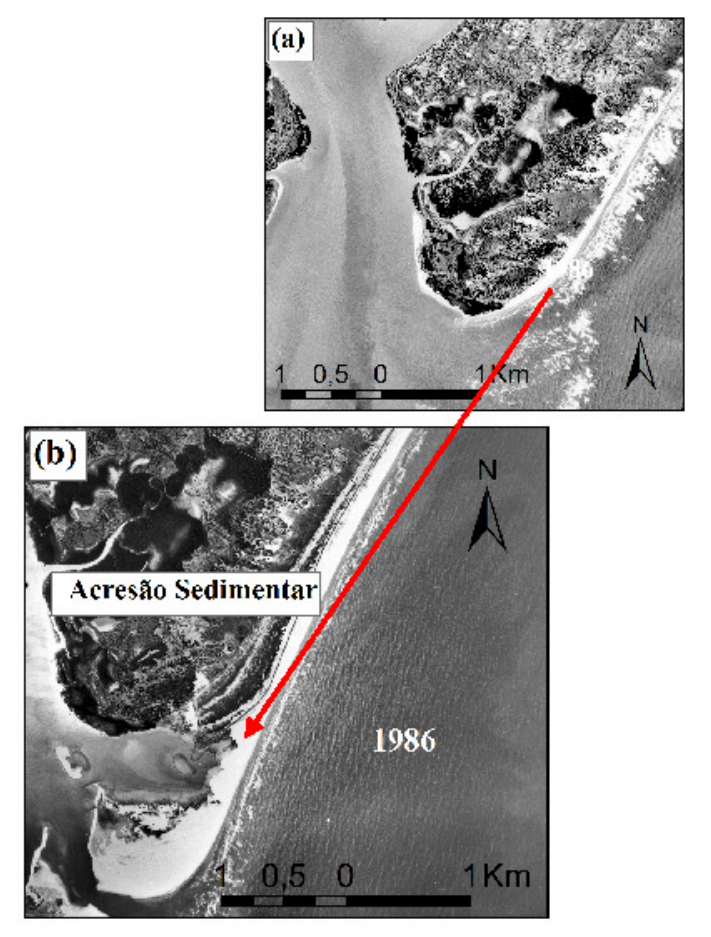

Entre 1986 e 2008, houve decréscimo de 1,2\% da área desta unidade em função de um processo erosivo no local mencionado.

$\mathrm{O}$ aumento da unidade Intervenção Antrópica nesta área deu-se a partir do final da década de 80, sendo também responsável pela redução da unidade Praia/Duna Frontal, só que em menor proporção.

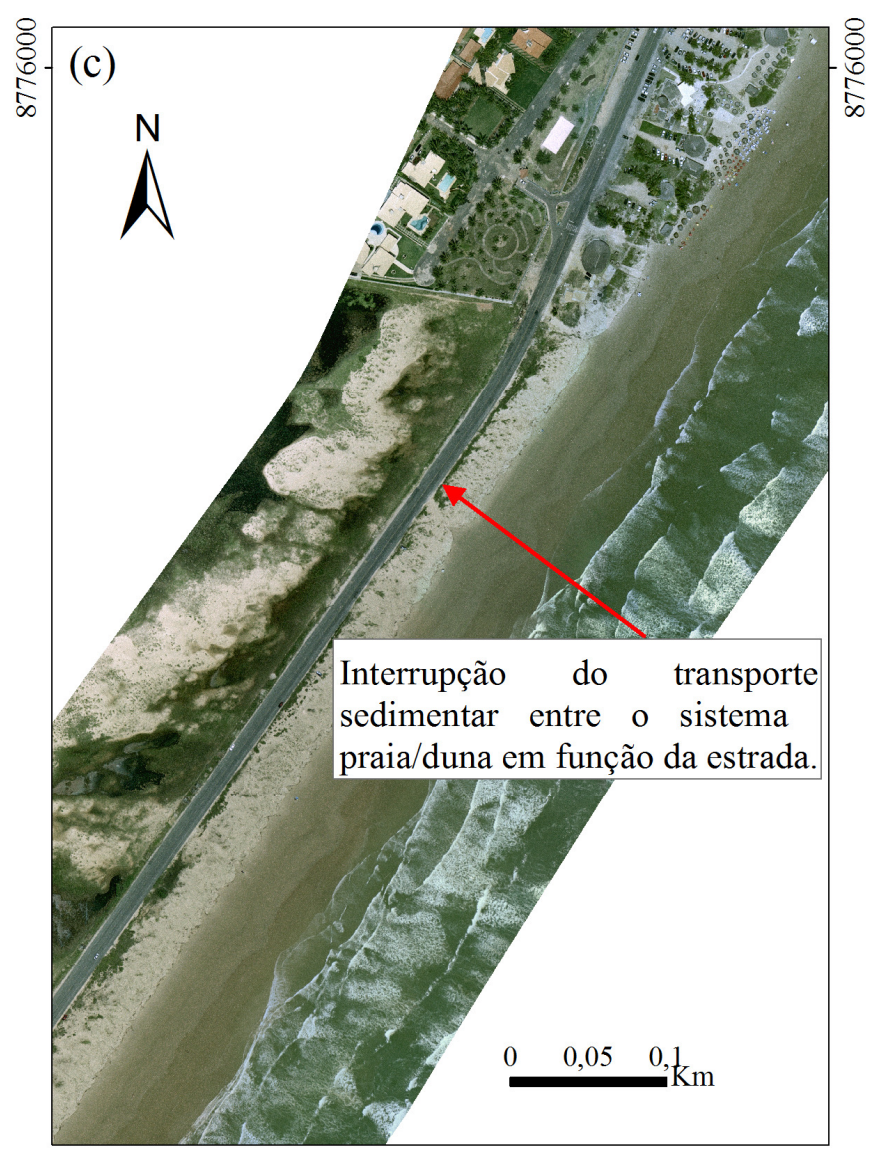

Figura 4. Modificações naturais e antrópicas na Unidade de Paisagem Praia/Duna Frontal. Fonte: (a e b) Fotografias aéreas de 1965 e 1986. (b) Ortofotos de 2008. Organização: Elaboração da Autora.

A construção de uma rodovia pavimentada sobre as unidades de Duna/Interduna e Praia/Duna Frontal ocasionou a interrupção do transporte sedimentar entre o sistema praial e as dunas (Figura 4c).

A unidade Planície de Maré não apresentou modificações consideráveis entre 1965 e 1971. De 1986 até 2003 houve acréscimo da área em cerca de $0,5 \%$ em função da colmatação de sedimentos no corpo aquoso situado na retaguarda da praia e, por isso, protegido da ação das ondas. De 2003 até 2008 houve uma redução de $0,9 \%$ da área em função da erosão costeira. Esta unidade apresentou uma tendência diferenciada das demais unidades, uma vez que apresentou variações em sua área, predominantemente, em função da dinâmica natural.

A Unidade Intervenção Antrópica, conforme citado anteriormente, desenvolveu-se sobre as diferentes Unidades de Paisagem Natural, e apresentou um crescimento em sua área representativo a partir de 1978 (Gráfico 1). As Áreas Parcialmente Ocupadas tiveram maior aumento entre 1978 e 1986, totalizando 2,7\%. Entre 1986 e 2003, o aumento foi de apenas 0,3\%. Por outro lado, a Área Ocupada, teve maior expansão entre o período de 1986 até 2003, com aumento de 5,9\%. Entre 1986 e 2003 ocorreu a ocupação efetiva de áreas antes loteadas. Já entre os anos de 2003 e 2008, tornou a ocorrer aumento de $1,1 \%$ das Áreas Parcialmente Ocupadas e de 
2,4\% das Áreas Ocupadas. O período total investigado (1965 a 2008) mostra que houve um aumento de 10,2\% da Área Ocupada e, de 5,7\% das Áreas Parcialmente Ocupadas, totalizando um acréscimo em sua área de 15,9\% da paisagem.

O aumento da construção de estradas ou vias de ligação foi fundamental para possibilitar a ocupação da área de estudo. Entre 1965 e 2008, a construção e pavimentação de novas estradas resultou em um aumento de cerca de $50 \mathrm{~km}$ de estradas pavimentadas e, aproximadamente, 65 km de estradas não-pavimentadas.

\section{Antropogenização da Paisagem Costeira da Zona de Expansão}

O processo, denominado por Rodriguez, Silva e Cavalcanti (2004) de antropogenização da paisagem (também conhecido por transformação da Paisagem em Antropo-Natural) foi verificado na área investigada, em razão do aumento contínuo da ocupação na área supracitada.

É importante ressaltar que, apesar de determinadas unidades apresentarem influência da dinâmica antrópica, cada unidade por mais antropizada que seja, ainda será submetida às leis da dinâmica natural (Bólos, 1992, Lang e
Blaschke, 2009, Rodriguez, Silva e Cavalcante, 2004). Isto implicará em alguns conflitos de uso, uma vez que, o aumento da ocupação torna a paisagem menos estável. Assim, qualquer processo de cunho natural que ocorra nessas paisagens pode ser amplificado e, desta forma, se tornar extremamente problemático para a ocupação humana (Rodriguez, Silva e Cavalcante, 2004). Junto a este fato, soma-se a forma como a ocupação se especializa na paisagem, que em áreas costeiras, a exemplo da Zona de Expansão de Aracaju, geralmente, são incompatíveis com o arranjo espacial da distribuição dos elementos naturais.

$\mathrm{Na}$ área investigada, a ocupação que se deu em maior parte sobre o Terraço Marinho, interrompeu as sequências dos cordões litorâneos (Figura 5). O aumento de área edificada e a disposição irregular destas têm gerado problemas enormes para a área, principalmente no que concerne a drenagem da água pluvial e da água subterrânea.

As áreas de inter-cordões são naturalmente vulneráveis a alagamentos, assim sendo, a ocupação humana sobre esta unidade potencializa esses alagamentos em períodos chuvosos.

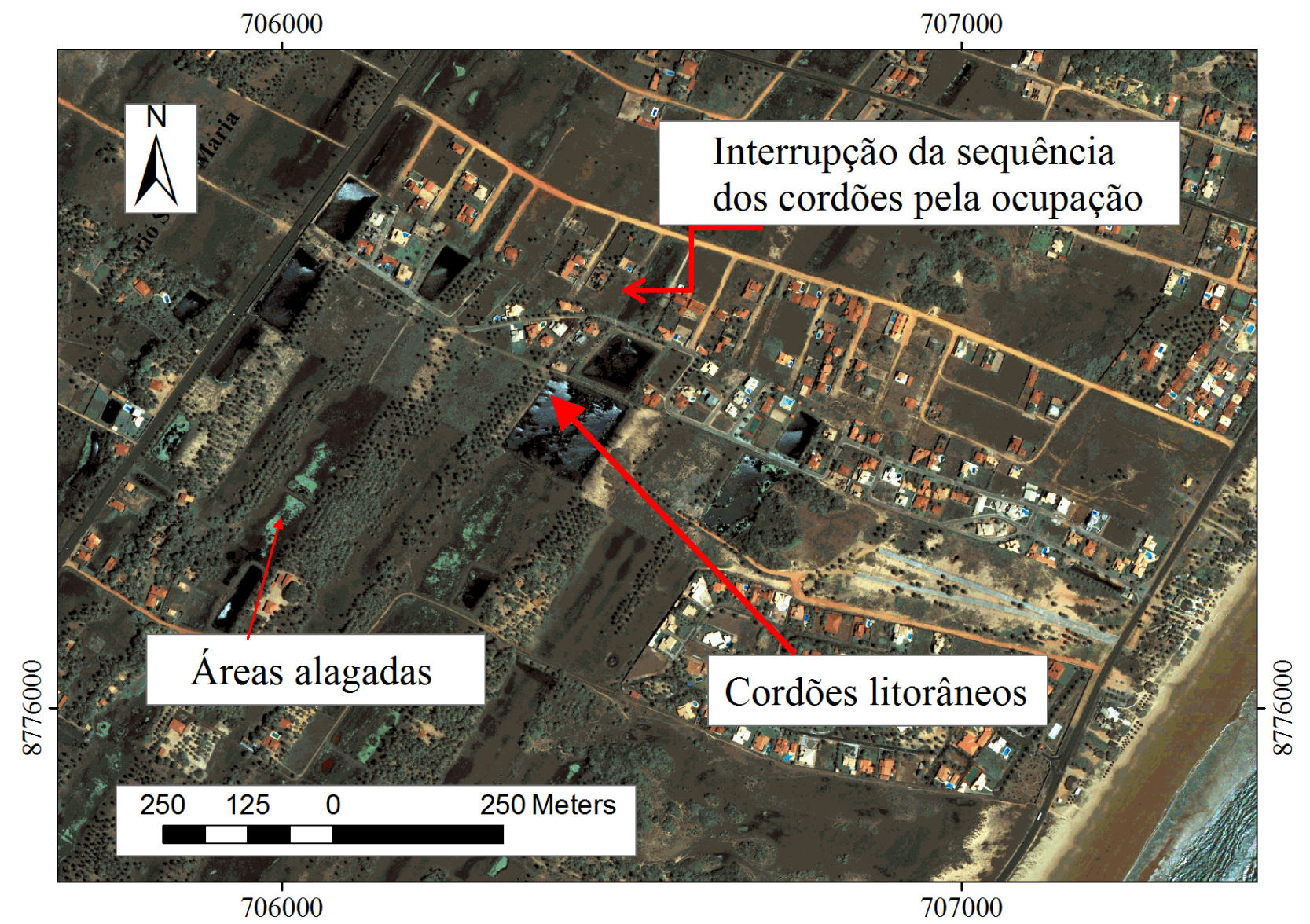

Figura 5. Ocupação humana sobre o terraço marinho e suas consequências na Zona de Expansão em 2003. Fonte: Imagem de satélite QuickBird (2003). Organização: Elaboração da autora. 
O modelo de Mancha-Corredor-Matriz, o qual foi adaptado e aplicado à Zona de Expansão, mostrou que tanto em 1971 quanto em 2008, a matriz é natural, ou seja, corresponde a mais de $50 \%$ da paisagem, enquanto que a mancha, menor de $50 \%$, é de origem antrópica (Figura 6).

Com base em Lang e Blaschke (2009), determinadas paisagens podem ter sua estrutura modificada em função da alteração das áreas de matrizes e manchas. Assim, se uma paisagem, antes considerada matriz natural, for antropizada

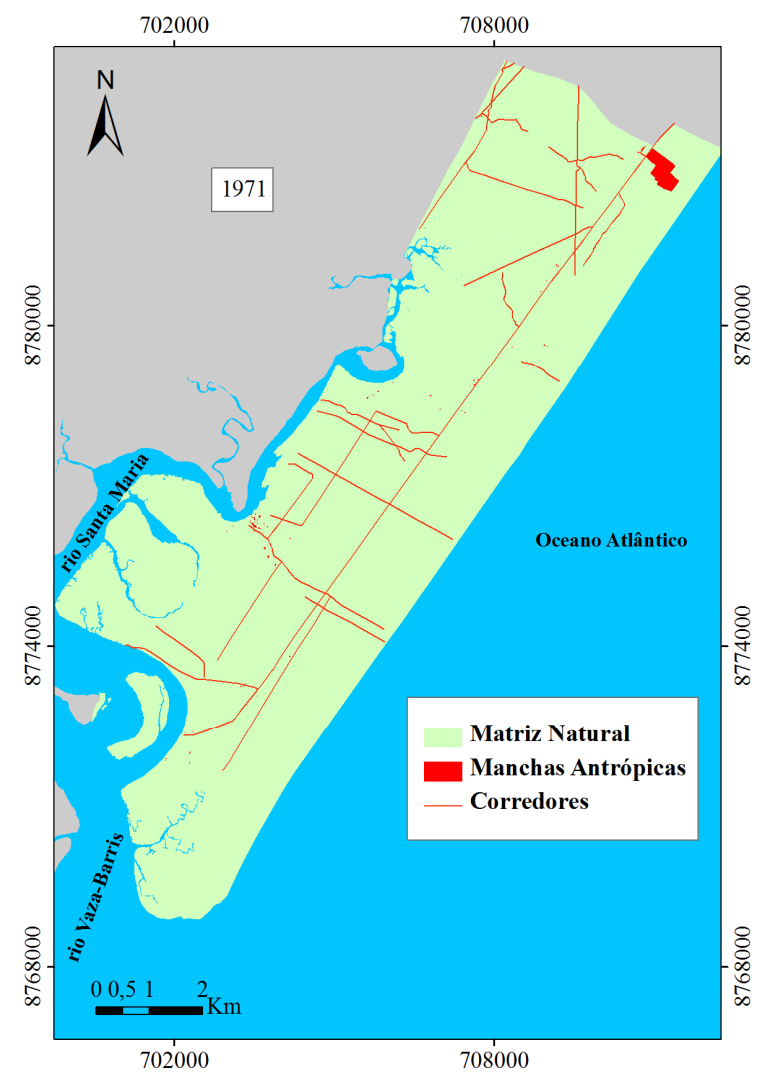

intensamente, terá sua matriz modificada para antropizada, enquanto que as áreas naturais se tornarão manchas.

$\mathrm{Na}$ Zona de Expansão, a área, em quilômetros quadrados, da unidade de Intervenção Antrópica na paisagem aumentou no período analisado. Destarte, a referida paisagem pode futuramente ter sua matriz alterada, caso a ocupação continue aumentando no ritmo acelerado apresentado nas últimas quatro décadas.

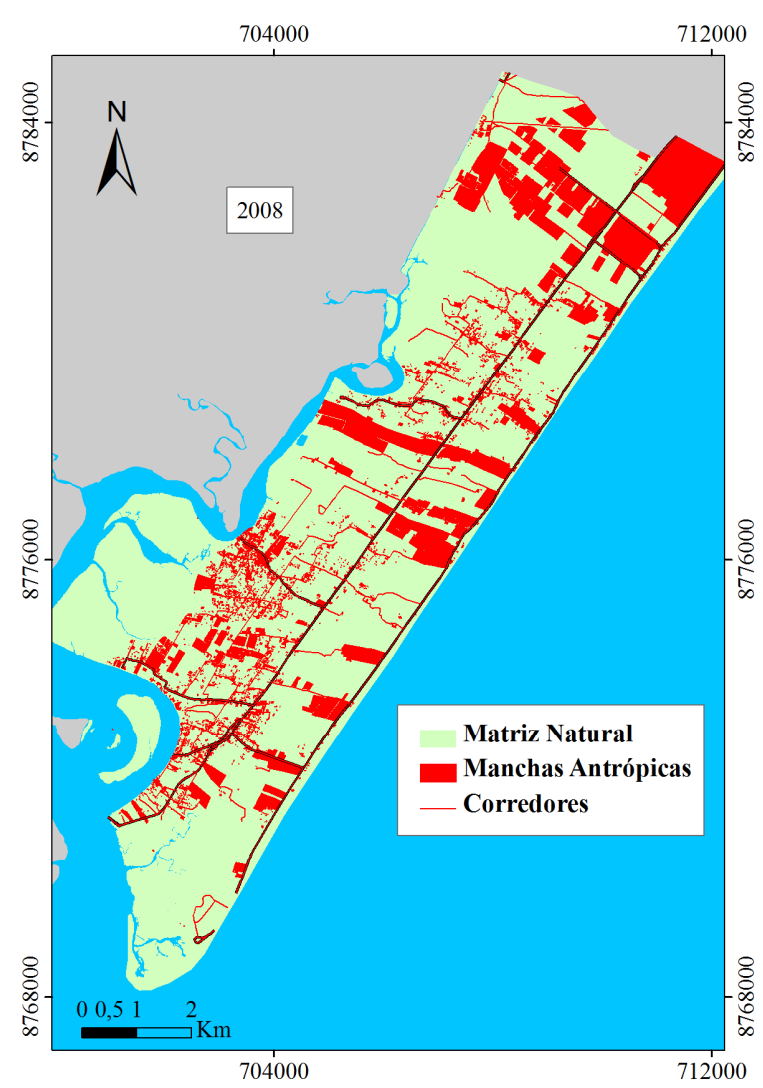

Figura 6. Modelo de Mancha-Corredor-Matriz aplicado à Zona de Expansão de Aracaju entre 1971 e 2008. Fonte: Fotografias aéreas de 1971 e Imagens de Satélites QuickBird de 2008. Organização: Elaboração da autora.

Apesar do crescimento populacional verificado na área estudada no período de 1971 a 2008 (IBGE, 2010), as Unidades de Paisagem Natural ainda mantiveram uma área $\left(\mathrm{em}^{2} \mathrm{~km}^{2}\right.$ maior do que a Unidade Intervenção Antrópica.

Ao analisar apenas os dados de variação da área das unidades de paisagem (Gráfico 1), separadamente da análise dos mapas (vide Figuras 2 e 3), obtêm-se uma percepção errônea, uma vez que tais dados passam a ideia de uma paisagem pouco antropizada.

Para exemplificar este fato, retomam-se os valores obtidos no ano de 2008. Da área total de $65,4 \mathrm{~km}^{2}$ da Zona de Expansão, apenas $11,2 \mathrm{~km}^{2}$ $(16,5 \%)$ correspondia a Unidade de Intervenção Antrópica.
Entretanto, este fato verificado na Zona de Expansão de Aracaju, pode ser justificado na literatura de Lang e Blaschke (2009). Estes autores consideram que existem paisagens nas quais, após a aplicação do método de Medidas da Estrutura (Quantificação da Paisagem), mostram uma falsa impressão de que a paisagem é pouco antropizada. Isto ocorre quando a perda de área absoluta é relativamente pequena, em função de um padrão de ocupação disperso, atribuindo à paisagem uma característica de retalhamento. Este fato impossibilita a quantificação exata do nível de intervenção antrópica, exigindo assim uma análise de cunho qualitativo da paisagem.

$\mathrm{Na}$ Zona de Expansão de Aracaju, o contínuo crescimento de uma ocupação dispersa não 
promoveu uma perda significativa de área das Unidades de Paisagem Natural. Assim, a análise qualitativa confere a área de estudo uma característica de antropizada, pelo efeito do alto grau de retalhamento da ocupação. Essa particularidade apontada na Zona de Expansão corrobora as concepções de Lang e Blaschke (2009) que, apesar de apontar a enorme importância de quantificar a paisagem, esclarece que esta não pode ser analisada apenas quantitativamente, em função da sua complexidade.

\section{Conclusões}

O estudo histórico-evolutivo das unidades de paisagem da Zona de Expansão de Aracaju, no período de 1965 a 2008, revelou que as mudanças na paisagem ocorreram decorrentes da ação conjunta entre os estruturantes físicos e antrópicos.

Este estudo revelou, ainda, que ao longo de 43 anos, a Unidade de Intervenção Antrópica avançou sobre as Unidades de Paisagem Natural. As unidades Terraço Marinho e Duna/Interduna foram aquelas que sofreram maior alteração no período investigado, em função do aumento da Unidade de Intervenção Antrópica. Apenas a Planície de Maré não foi afetada consideravelmente pela intervenção antrópica.

Juntamente à análise posta, identificou-se que a ocupação sobre as unidades de paisagem gerou um padrão reticular que não levou em consideração a disposição espacial das unidades naturais, o que acarretou no aterramento de lagoas e, na destruição de feições como os cordões litorâneos e dunas.

Notou-se que apesar do considerável aumento da ação humana, a Unidade de Intervenção Antrópica ainda não é maior em área do que a Unidade de Paisagem Natural. Este fato também foi comprovado após a aplicação do modelo de Mancha-Corredor-Matriz (Lang e Blaschke, 2009), uma vez que a Zona de Expansão apresenta uma matriz natural, permeada por manchas de origem antrópica. Apesar de ser considerada ainda uma matriz natural, a intervenção humana foi suficiente para modificar a estrutura e a função da paisagem, uma vez que esta área deixou de ser uma paisagem com preponderância de características naturais.

A intensificação da intervenção antrópica influenciou na transformação da paisagem da Zona de Expansão de Aracaju. No entanto, há de se considerar a existência de uma mudança da paisagem, independente da ação antrópica, regulada por agentes naturais específicos que contribuem para mudança das unidades, como as dunas/interdunas, a planície de maré e a praia/linha de costa.

Diante da situação crescente de expansão da ocupação da Zona de Expansão de Aracaju, são necessárias que sejam adotadas ações corretivas e preventivas no que concerne ao ordenamento de sua ocupação presente e futura, respectivamente, a fim de se evitar prejuízos socioeconômicos e danos ambientais.

\section{Agradecimentos}

As autoras agradecem ao Conselho Nacional de Desenvolvimento Científico e TecnológicoCNPq pela concessão de bolsa de Mestrado.

\section{Referências}

Bertrand, G., 2004. Paisagem e Geografia Física Global. Esboço Metodológico. Caderno de Ciências da Terra, Instituto de Geografia da Universidade Federal de São Paulo, n. 13, 1972. Traduzido por: Olga Cruz. R.RA'E GA 8, 141-152.

Bittencourt, A.C.S.P., Martin, L., Dominguez, J.M.L., Ferreira, Y.A., 1983. Evolução Paleogeográfica Quaternária da Costa do Estado de Sergipe e da Costa Sul do estado de Alagoas. Revista Brasileira de Geociências 13, 93-97.

Bólos, M.de., 1991. Manual de Ciencia Del Paisaje: Teoría, métodos y aplicaciones. Masson, Barcelona.

Davis, R., Fitzgerald, D., 2004. Beach and Coasts. Blackwell Science Ltd. Austrália.

Esteves, S.L., 2003. Estado-da-arte dos métodos de mapeamento da linha de costa. Instituto de Geociências, UFRS.

Ingegnoli, V., 2002. Landscape Ecology: A widening Foundation. Berlin, Heidelberg, New York, Barcelona, Hong Kong; London, Milan, Paris, Tokyo. Springer.

Lang, S., Blaschke, T., 2009. Análise da Paisagem com SIG. Oficina de Textos. Tradução de Hermann Kux. São Paulo.

Rodriguez, J.M.M., Silva. E.V.da., Cavalcanti, A.P.B., 2004. Geoecologia das Paisagens: Uma visão geossistêmica da análise ambiental. Editora UFC, Fortaleza.

Stive, M.J.F., Aarninkhof, S.G.J., Hamm, J., Hanson, H., Larson, M., Wijnberg, M.K., Nicholls, R.J., Capobianco, M., 2002. Variability of shore and shoreline evolution. Coastal Engineering 47, 211-235.

Terich, T.A., 1987. Living with the Shore of Puget Sound and the Georgia Strait. Duke University Press. Durham. 
Revista Brasileira de Geografia Física Vol. 08 N. 02 (2015) 391-401

Tricart, J., 1976. A Geomorfologia nos Estudos Boletim Geográfico 34, 15-42. Integrados de Ordenação do Meio Natural. 